\title{
Boron Neutron Capture Therapy of Cancer as a Part of Modern Nanomedicine
}

\author{
Alexander V. Safronov* \\ Institute of Nano and Molecular Medicine, University of Missouri-Columbia, USA \\ ${ }^{*}$ Corresponding author: Institute of Nano and Molecular Medicine, School of Medicine, University of Missouri- \\ Columbia, 1514 Research Park Drive, Columbia, MO 65211, USA, E-mail: safronova@missouri.edu
}

Boron neutron capture therapy (BNCT) is a method of cancer therapy with a simple idea behind it. Positioning a certain amount of ${ }^{10} \mathrm{~B}$-enriched boron-containing compounds into tumor cells with subsequent irradiation of the tumor tissue by thermal or epithermal neutrons causes tumor damage and death. The mechanism of the tumor cell damage during BNCT is based on the capture-fission reaction between the boron-10 nucleus and a neutron resulting in an $\alpha$-particle release inside the cell. A successful BNCT therapeutic agent must obey several requirements, most importantly it should (1) selectively accumulate in tumor cells, (2) show certain levels of tumor-to-blood concentration ratios (3 and higher), and (3) provide the therapeutic concentration of ${ }^{10} \mathrm{~B}$ in tumor cells (at least $20 \mu \mathrm{g}$ of ${ }^{10} \mathrm{~B} / \mathrm{g}$ of tumor).

During the last 60 years, BNCT application in medicine was slowed down by two main factors. The first was almost exclusive concentration of the efforts on studying BNCT effect for brain tumors such as Glioblastoma multiforme which is very difficult to treat [1]. The second factor was the use of only two compounds for clinical trials: boronophenylalanine (BPA) and sodium borocaptate (BSH, thiol derivative of the $\left[\mathrm{B}_{12} \mathrm{H}_{12}\right]^{2-}$ polyhedral borane anion). Although both compounds did not perform very well, they did not require any special delivery techniques and could be administered in water solutions intravenously. Unsatisfactory results of first clinical studies inhibited the development of BNCT for decades.

The new era of BNCT started in the 1990's when a novel approach to the delivery of boron compounds (different from BPA and BSH) into tumors in hydrophilic cores of liposomes was suggested [2]. The liposome formulations were later improved by incorporating boron-containing molecules both into the lipid bilayer and into the hydrophilic core. The range of boron-containing compounds used for the liposome bilayer formation/incorporation includes amphiphilic nido-carboranes [3,4], nido-carborane and polyhedral borane analogs of lipids [5], carborane- and metallacarboranesubstituted cholesterols and cholesterol mimics [6-8]. Compounds used for incorporation into the hydrophilic core include BSH, salts hydrolytically stable boranes such as $\mathrm{Na}_{3}\left[\mathrm{~B}_{20} \mathrm{H}_{17} \mathrm{NH}_{3}\right]$, and nidocarboranes.

After nanomaterials became a 'hot topic' in 2000's, a new approach to the BNCT agents delivery via nanoparticles started to develop. Three major types of delivery vehicles were created. The first type contains a BNCT-neutral core containing the therapeutic agent on the periphery. The most common materials for the core formation are gold [9] and silica [10]. The periphery of the core, in the case of gold nanoparticles, was functionalized by closo-carboranes and connected to the core by organic linkers. For the mesoporous silica nanoparticles, the therapeutic agent was incorporated in solution into the pores of the nanoparticles. The core of the second type nanoparticles contains therapeutic agent while the periphery contains targeting groups or groups increasing solubility, such as PEGs. The core may be constructed from boron carbide [11], elementary boron [12], borosilicate glass [13], boron phosphate [14], or boron-containing organic polymer [15]. The third kind of nanoparticles for BNCT contains therapeutic agent both in the core and on the periphery of the particle. Unimolecular nanoparticles of this type (closomers) are constructed based on a $\left[\mathrm{B}_{12}(\mathrm{OH})_{12}\right]^{2-}$ core functionalized by twelve nido-carboranes using alkyl linkers [16].

Another type of nanomaterial carriers for BNCT applications started developing only very recently. These are single-walled carbon nanotubes [17] and silicon nanowires [18] covered with physisorbed ortho-carborane and $\mathrm{BSH}$, respectively.

It would be wrong to conclude that all problems of BNCT were solved with the development of new boron delivery methods and materials. The main problem of the BNCT as a method is lack of clinical studies of the new materials. Most of the modern papers on BNCT report 'potential' BNCT agents; a lot of papers are purely synthetic and don't even include cell studies. And it seems that in some cases the abbreviation BNCT may become a 'golden ticket' for authors who just want to publish their current study without intent to continue.

In spite of the named problems, there are positive moments in the recent development of BNCT. First, many different cancer models (not just one) are being studied such as head and neck cancers, colorectal cancer, melanoma, small-cell lung cancer, breast cancer and others. Second, BNCT studies which started in the 1950's as an American project nowadays are being carried out in many other countries of the world: Japan, Canada, UK, Argentina, Sweden, Italy, Finland, Netherlands, and Russia. Unfairly forgotten for many years, recently BNCT started an explosive development incorporating 
advances in chemistry, biology, medicine, and nuclear technology.

Hopefully, it will not take another sixty years for BNCT to become a routine clinical method.

\section{References}

1. Lawson HC, Sampath P, Bohan E, Park MC, Hussain N, et al. (2007) Interstitial chemotherapy for malignant gliomas: the Johns Hopkins experience. J Neurooncol 83: 61-70.

2. Shelly K, Feakes DA, Hawthorne MF, Schmidt PG, Krisch TA, et al. (1992) Model studies directed toward the boron neutron-capture therapy of cancer: boron delivery to murine tumors with liposomes. Proc Natl Acad Sci U S A 89: 9039-9043.

3. Heber EM, Kueffer PJ, Lee MW Jr, Hawthorne MF, Garabalino MA, et al. (2012) Boron delivery with liposomes for boron neutron capture therapy (BNCT): biodistribution studies in an experimental model of oral cancer demonstrating therapeutic potential. Radiat Environ Biophys 51: 195-204.

4. Kueffer PJ, Maitz CA, Khan AA, Schuster SA, Shlyakhtina NI, et al. (2013) Boron neutron capture therapy demonstrated in mice bearing EMT6 tumors following selective delivery of boron by rationally designed liposomes. Proc Natl Acad Sci U S A 110: 6512-6517.

5. Nakamura H (2013) Boron lipid-based liposomal boron delivery system for neutron capture therapy: recent development and future perspective. Future Med Chem 5: 715-730.

6. Gifford I, Vreeland W, Grdanovska S, Burgett E, Kalinich J, et al. (2014) Liposome-based delivery of a boron-containing cholesteryl ester for high-LET particle-induced damage of prostate cancer cells: a boron neutron capture therapy study. Int J Radiat Biol 90: 480-485.

7. Białek-Pietras $M$, Olejniczak $A B$, Tachikawa $S$, Nakamura H, Leśnikowsk ZJ (2013) Towards new boron carriers for boron neutron capture therapy: metallacarboranes bearing cobalt, iron and chromium and their cholestero conjugates. Bioorg Med Chem 21: 1136-1142.

8. Calabrese G1, Nesnas JJ, Barbu E, Fatouros D, Tsibouklis J (2012) The formulation of polyhedral boranes for the boron neutron capture therapy of cancer. Drug Discov Today 17: 153-159.
9. Ciani L, Bortolussi S, Postuma I, Cansolino L, Ferrari C, et al. (2013) Rational design of gold nanoparticles functionalized with carboranes for application in Boron Neutron Capture Therapy. Int J Pharm 458: 340-346.

10. Lai CH, Lai NC, Chuang YJ, Chou FI, Yang CM, et al. (2013) Trivalent galactosyl-functionalized mesoporous silica nanoparticles as a target-specific delivery system for boron neutron capture therapy. Nanoscale 5: 9412-9418.

11. Mortensen MW1, Sørensen PG, Björkdahl O, Jensen MR, Gundersen HJ, et al. (2006) Preparation and characterization of Boron carbide nanoparticles for use as a novel agent in T cell-guided boron neutron capture therapy. Appl Radiat Isot 64: 315-324.

12. Gao Z, Walton NI, Malugin A, Ghandehari H, Zharov IJ (2012) Preparation of dopamine-modified boron nanoparticles. Mater Chem 22: 877-882.

13. Grandi S, Spinella A, Tomasi C, Bruni G, Fagnoni M, et al. Synthesis and characterisation of functionalized borosilicate nanoparticles for boron neutron capture therapy applications. Journal of Sol-Gel Science and Technology 64 : 358-366.

14. Achilli C, Grandi S, Ciana A, Guidetti GF, Malara A, et al. (2014) Biocompatibility of functionalized boron phosphate (BPO4) nanoparticles for boron neutron capture therapy (BNCT) application. Nanomedicine 10: 589597.

15. Sumitani S, Nagasaki Y (2012) Boron neutron capture therapy assisted by boron-conjugated nanoparticles. Polym J 44: 522-530.

16. Ma L, Hamdi J, Wong F, Hawthorne MF (2006) Closomers of high boron content: synthesis, characterization, and potential application as unimolecular nanoparticle delivery vehicles for boron neutron capture therapy. Inorg Chem 45: $278-285$

17. Yannopoulos SN, Zouganelis GD, Nurmohamed S, Smith JR, Bouropoulos $\mathrm{N}$, et al. (2010) Physisorbed o-carborane onto lyso-phosphatidylcholinefunctionalized, single-walled carbon nanotubes: a potential carrier system for the therapeutic delivery of boron. Nanotechnology 21: 85101.

18. Jiang K, Coffer JL, Gillen JG, Brewer TM (2010) Incorporation of Cesium Borocaptate onto Silicon Nanowires as a Delivery Vehicle for Boron Neutron Capture Therapy. Chem Mater 22: 279-281. 